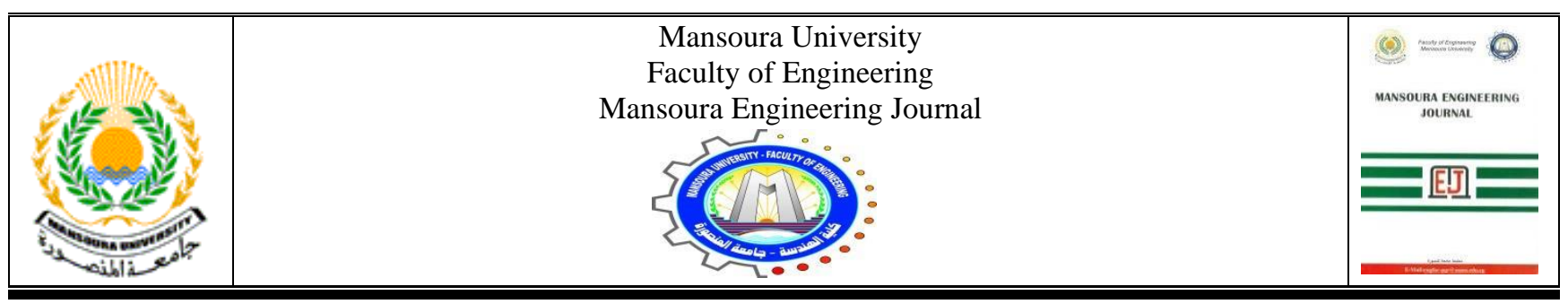

\title{
Analysis of Stand-Alone Micro-grid with Photovoltaic, Diesel Generators and SOFC
}

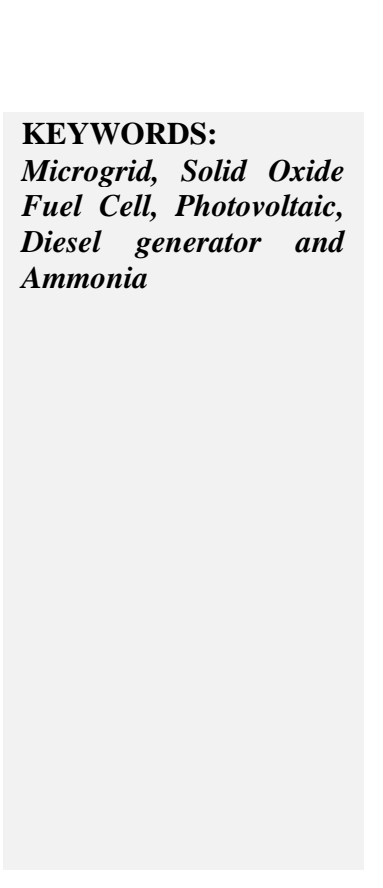

\author{
Abeer Galal and M.Said
}

\section{INTRODUCTION}

$\mathrm{R}$ Enewable energy resources are several such as photovoltaic, wind energy and fuel cell. These sources are used for several applications from satellite application to indoor utilization [1-4]. This paper is interested with photovoltaic and fuel cell. Ammonia is a promising hydrogen carrier because of its high hydrogen density, low production cost and ease in liquefaction and transport. The hydrogen in ammonia is $107 \mathrm{~kg}-\mathrm{H}_{2} / \mathrm{m}^{3}$ at 1.0 MPa and $25^{\circ} \mathrm{C}$ [5]. Furthermore, fuel cells have recently been

Received: (12 August, 2020) - Revised: (5 October, 2020) - Accepted: (12 November, 2020)

Corresponding Author: Mokhtar Said, is with Fayoum University, Egypt. He is now with the Department of Electrical engineering, Faculty of Engineering (e-mail: msi01@fayoum.edu.eg).

Abeer Galal is with the Electrical Engineering Department, Faculty of Engineering, Fayoum University (e-mail: ags02@fayoum.edu.eg). the focus of great interest as a distributed generation technology [6, 7]. A hybrid system of solid oxide fuel cell (SOFC) and polymer electrolyte fuel cell (PEM) is illustrated $[8,9]$. SOFC is a high-temperature technology, thus its exhaust streams will tend to have high temperature [10]. In addition, photovoltaic power presents the most economically viable renewable solution. A fuel cell micro-grid with a smallscale was studied for a cold region [11]. Moreover, high grade exhaust heat can enable with high-efficiency by triple combined cycle combinations such as SOFC/gas turbine/steam turbine [12-14]. For example, development of the independent micro-grid by the interconnection of two or more diesel engine generators installed in buildings is expected at an early stage. Moreover, the engineering development in regard of improvement of the power-generation efficiency of an independent micro-grid by the interconnection of SOFC described in the top is expected. Studies about ammonia as a carrier for hydrogen are illustrated [15], storage and transportation are introduced [16], and kinetic enhancement of ammonia decomposition is shown [17], and the efficiency of 
production is improved [18]. In this research, the energy flow analysis with ammonia $\left(\mathrm{NH}_{3}\right)$ used as hydrogenated fuels is discussed. The transmission system fluctuations are controlled by fuel cells.

In this paper, a proposal system of a stand-alone microgrid with the number control of diesel engine generators (DEGs), SOFCs and photovoltaic system (PV) is investigated with ammonia to a city, Egypt. The hydrogen supply using Ammonia $\left(\mathrm{NH}_{3}\right)$ energy flows is discussed in this work. This study clarifies a need with numerical analysis of the energy exchanges involved by using ammonia as hydrogen supply chain. The objective of this study is to clarify the power generation output characteristics and the operation of two methods of the proposal system. The operation conditions of an independent micro-grid with SOFCs, DEGs and PV power generation were investigated to an extensive treatment for hydrogen supply chain efficiency. Furthermore, the optimal operation of SOFCs with DEGs and PV is developed to minimize the system fuel consumption. This research study has finished up to the strategy of energy management is essential for the optimal utilization of the power-hydrogenpower systems as well as the optimization of the hybrid system. The proposed hybrid stand-alone system has several advantages such as economic development, energy security and feeding remote communities with energy of low costs that is helped in future energy sustainability and cleanness of it.

\section{II. - -LAYOUT OF THE PROPOSAL SYSTEM}

This article proposes a hybrid system with using hydrogen carriers for long-term energy storage. The power to hydrogen to power system comprises three components; the electrizer, hydrogen storage and fuel cell is shown in Fig. (1). the proposed approach is applied to a case study of a hypothetical power-system of a stand-alone micro-grid. A combined system of diesel engine generators (DEGs), fuel cells (SOFCs) and large-scale PV system are used to supply energy to a demand side is shown in Fig.2. The proposed system is used to supply energy to a stand-alone micro-grid in a city, Egypt. A large-scale PV system with 18\%power generation efficiency and $1000 \mathrm{~m}^{2}$ is proposed in our hybrid system. Furthermore, a block diagram of the proposed system with hydrogen and dehydrogenated process is shown in Fig. (2). The power balance equation in sampling time $t$ of the proposed system is shown in Eq. (1). Left side is the output power and the right side is the consumption power. The output $e_{p v}$ of the photovoltaic system, output $e_{\text {sofc }}$ of SOFC power generation, and output $e_{e g}$ of the engine generators are supplied to the demand side. The electric power is consumed by the electricity demand $\Delta e_{\text {load }}$ of the right-hand side of Eq.(1), power consumption $\Delta e_{h p}$, and loss $\Delta e_{\text {loss }}$ are the loss of a power conditioner for PV and the loss of all generators. The exhaust heat from engine generators and SOFC are used to supply heat to the water electrizer.

$$
e_{p v}+e_{s o f c}+e_{e g}=\Delta e_{h p}+\Delta e_{l o a d}+\Delta e_{l o s s}
$$
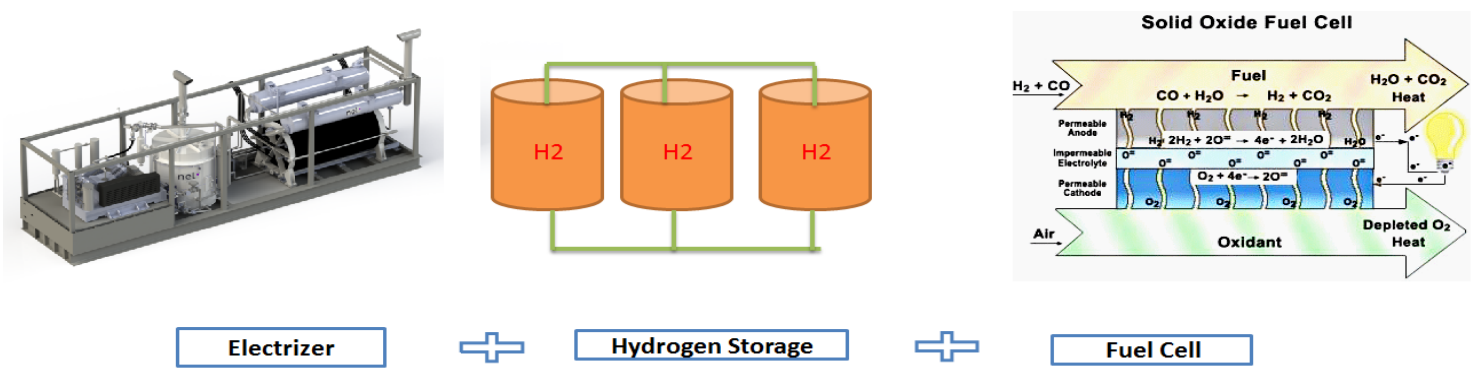

fig1. Power to hydrogen to power system components

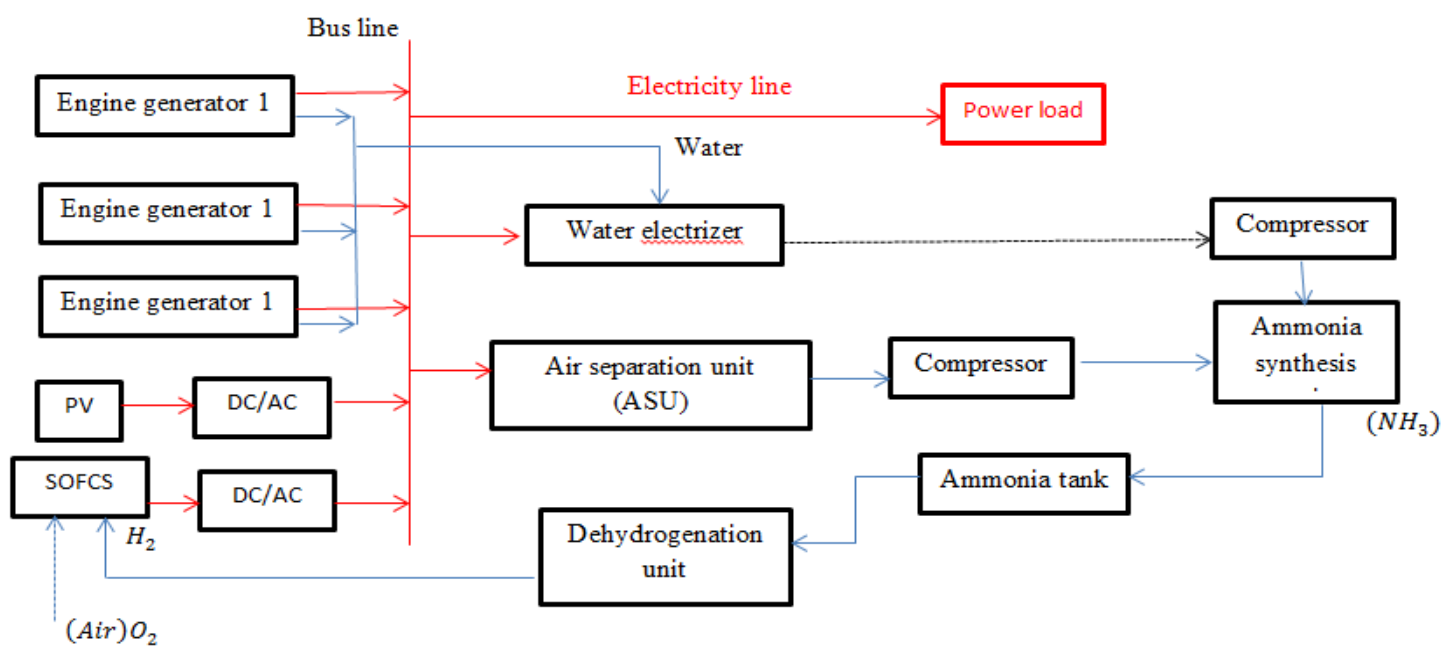

fig2. Block diagram of the proposed system 


\section{SPECIFICATION OF THE PROPOSAL SYSTEM COMPONENT}

\subsection{Water Electrizer}

The components of the water electrolysis system are shown in Fig.3 (a). $\eta$ in this figure is efficiency, $\eta^{\prime}$ is timedependent efficiency, $e$ is energy, $e_{h g, 3}$ is obtained from using the amount of electricity $J_{\text {we }}$ supplied to the water electrizer, The electrizer efficiency $\eta_{w e}$ is calculated, in which $\eta_{j}$ and $\eta_{e}$ are the efficiency of electricity and efficiency of voltage, respectively. In addition, water electrizer runs at efficiency varying from $70 \%$ to $90 \%$. The water electrizer is analyzed as a proton exchange membrane device. The efficiency of the water electrizer is $80 \%$. The enthalpy $e_{h g, 3}$ of hydrogen extract from the water electrizer in Fig. 3(a) is computed as the product of the electricity input to the water electrizer and the efficiency $J_{w e}$ of water electrolysis. Additionally, $e_{h g, 3}$ is calculated from using the input water electrizer electricity $J_{w e}$.

\subsection{Ammonia synthesize}

The ammonia mass production from chemical reaction between nitrogen and hydrogen should be at about $500{ }^{\circ} \mathrm{C}$ with pressure of 25 to $35 \mathrm{MPa}$ is shown in Eq. (2). The ammonia hydrogenation process uses hydrogen generated from the water electrizer and nitrogen spread out from air with a conversion rate of $90 \%$ [19]. Then, the ammonia gas is cooled to about $-30{ }^{\circ} \mathrm{C}$ in Eq. (3). Ammonia synthesis unit generates liquid ammonia that is stored in storage tank of ammonia. Ammonia synthesis systems explained in Fig3 (b).

$\mathrm{N}_{2}$ (gas) $+3 \mathrm{H}_{2}$ (gas) $\rightarrow 2 \mathrm{NH}_{3}($ gas $)-924 \mathrm{KJ} / \mathrm{mol}$

$\mathrm{NH}_{3}$ (gas) $\rightarrow \mathrm{NH}_{3}$ (liquid) $-21.49 \frac{\mathrm{KJ}}{\mathrm{mol}}$

The energy flows of this process are in Eqs. (4) to (7). The energy; $e_{h g, 4}$ input to the ammonia synthesis unit without the power consumption ( $\Delta e_{h g, c p}$ ) of the hydrogen compressor from the water electrizer output energy $\left(e_{h g, 3}\right)$. When the reaction efficiency; $\eta_{h u}$, generation of heat by ammonia synthesis; $\Delta e_{h u h}$, and the loss $\Delta e_{a s u}$ are considered, $e_{h g, 5}$ in equation(5) is the output energy from the ammonia synthesis unit. Equations (6) and (7) are the pump output and the energy in the ammonia storage tank. A pump is used to supply the generated energy from the hydrogenation unit to the ammonia tank. The pump power consumption is $\Delta e_{\text {pump }}$. Eqs (6) and (7) express the energy relationship between the pump and the ammonia tank outlet.

$e_{h g, 4}=e_{h g, 3}-\Delta e_{h g, c p}$

$e_{h g, 5}=\eta_{h u} \cdot e_{h g, 4}-\Delta e_{h u h}-\Delta e_{a s u}$

$e_{h g, 6}=e_{h g, 5}-\Delta e_{\text {pump }}$

$e_{h g, 7}=e_{h g, 6}$

\subsection{Dehydrogenation unit}

Dehydrogenation system is explained in Fig,3(b). Hydrogen is separated from ammonia by the dissociation reaction describes in equation (8). The dissociative reaction of hydrogen from the ammonia which requires temperatures of 400 to $800{ }^{\circ} \mathrm{C}$ at air pressure 400 to $800 \mathrm{~A} \mathrm{C}$ (Endothermic heat) is shown in figure 8. The energy used in the dehydrogenation process of ammonia $e_{h g, 7}$ is shown in Eq. (9) from Eq. (7). The energy $e_{d h, 1}$ absorbed by the dehydrogenation unit, the heat in the range 400-800 during the reaction is required for hydrogen dissociation at air pressure, and $\Delta e_{\text {hnit }}$ is the enthalpy of nitrogen. Then, the hydrogen is converted to electric power by solid-oxide fuel cells (SOFCs). The hydrogen output from the dehydrogenation unit is supplied to the SOFC and also the SOFC takes $O_{2}$ from air.

$$
\begin{gathered}
\mathrm{NH}_{3} \text { (gas) } \rightarrow 1.5 \mathrm{H}_{2}(\text { gas })+0.5 \mathrm{~N}_{2} \text { (gas) } \\
+92.4 \mathrm{KJ} / \mathrm{mol}
\end{gathered}
$$

Table 1 lists the conditions for the proposal system. The reaction temperature and conversion ratio of dehydrogenation unit are 800 and $90 \%$. The energy $e_{d h, 2}$ consumed by the dehydrogenation unit is obtained from the reaction efficiency $\eta_{d h}$, the heat required for hydrogen dissociation $\Delta e_{h s d}$, and the enthalpy $e_{\text {hnit }}$ of nitrogen.

$$
\begin{aligned}
& e_{d h, 1}^{\cdot}=e_{h g, 7} \\
& e_{d h, 2}^{\dot{u}_{h, 2}}=\eta_{d h} \cdot e_{d h, 1}+\Delta e_{h s d} \cdot e_{h n i t}
\end{aligned}
$$

Table 1

The ammonia synthesis Specifications

\begin{tabular}{l||l}
\multicolumn{1}{c||}{ Parameters } & \multicolumn{1}{c}{ Value } \\
\hline hydrogen compressor efficiency & $55 \%$ \\
\hline pressure of reaction & $35 \mathrm{MPa}$ \\
\hline Ratio of Conversion & $90 \%$ \\
\hline Pump efficiency & $80 \%$ \\
\hline heat storage efficiency & $95 \%$
\end{tabular}

Table 2

Specifications for SOFC

\begin{tabular}{l||l}
\multicolumn{1}{c||}{ Parameters } & \multicolumn{1}{c}{ Value } \\
\hline Power generation efficiency & $50 \%$ \\
\hline SOFC inverter efficiency & $95 \%$ \\
\hline Reaction pressure & $0.1 \mathrm{MPa}$ \\
\hline Efficiency of heat output & $40 \%$ \\
\hline hydrogen utilization factor & $90 \%$ \\
\hline air compressor efficiency & $55 \%$ \\
\hline Power conditioner efficiency & $90 \%$
\end{tabular}

\subsection{SOFC}

The fuel cells systems are identified in this research are solid oxide fuel cell (SOFCs). SOFCs efficiency and power generation is higher and it operates with gases variation so that SOFCs are becomes used widely. This work discusses the variation of load factors on the SOFC power generation efficiency and the SOFC accompanied by internal reforming. The specifications of SOFC used in this scheme are illustrated in table 2. The exhaust heat out from SOFCs is stored in the storage tank and it is used for the water electrizer. The working temperature of the SOFC is illustrated by the heat balance at which the enthalpy change of the anode and cathode, enthalpy change of the heat medium for temperature control, and the energetic change by chemical reaction of SOFCs are equal to the direct current electricity output, radiation of heat, and the quantity of heat transferred to the 
heat medium and the cell stack for cooling. A control of the working temperature of SOFCs is required to meet load fluctuation. The rated temperature is $850{ }^{\circ} \mathrm{C}$, and the amount of air and heat-medium circulation are based on maintenance of the rated temperature.

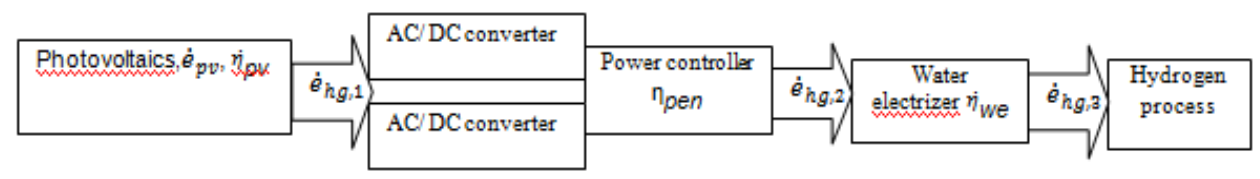

(a) Water electrizer system

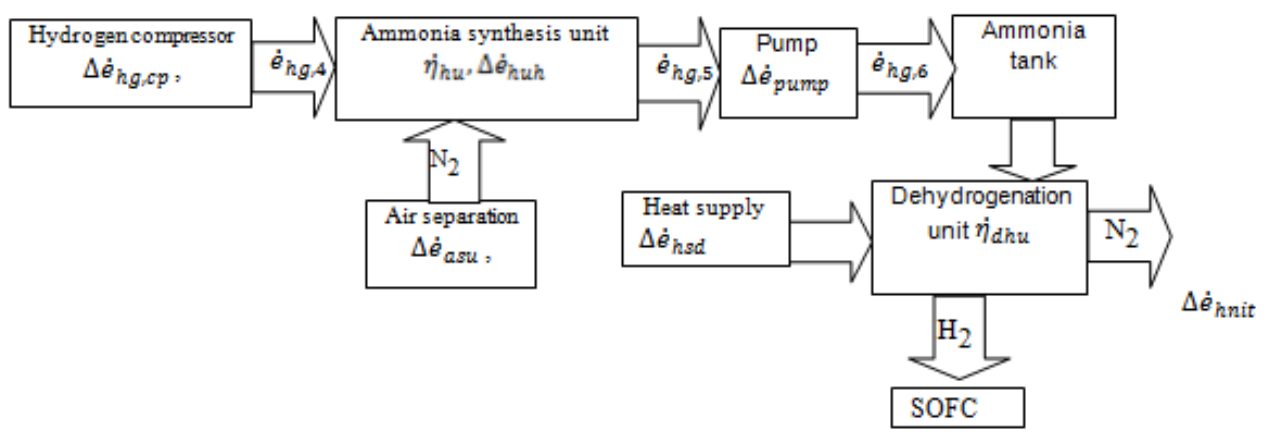

(b)Ammonia synthesis system and dehydrogenation

Fig.3 Energy flow (a) Water electrizer system, (b) Ammonia synthesis system and dehydrogenation

\subsection{Engine generators (DEGs)}

Three diesel engine generators (DEGs) of one MW each are suggested to supply energy to the demand side in Fig4 (a), this load is in Sharm El Sheikh City, Egypt. Fig4 (b) explain the outside air temperature of the city. Operations of DEGs are into two methods. One method with its maximum output rating with its maximum efficiencies is used. Method 2 with partial load operation is identified. The power generation efficiency $\eta_{\text {egei }}$ of each DEG is calculated from Eq. (12). The engine's maximum efficiency is $43.6 \%$. The load factor $\lambda_{e g i}$ of each DEG and the heat power are from Eq. (12) [16].

$$
\begin{gathered}
\eta_{\text {egei }}=\left(-0.00000356 \Lambda_{\text {egt }}^{2}+0.0014943 \Lambda_{\text {egt }}\right. \\
+0.3128) \eta_{g t i} \\
\eta_{e g h i}=0.001 . \lambda^{2}{ }_{e g i}-\lambda_{e g i}+41.6
\end{gathered}
$$

\subsection{Photovoltaic (PV) and load profile}

Recently there are many types of PV systems; the most commercially are polycrystalline silicon PV with power efficiency of $18 \%$ was considered in this research. Power output from a PV system can be calculated as equation (13):

$I_{p v}=\eta_{p v} * I_{G} * A_{p v}$

Where $I_{G}$ is global radiation $[\mathrm{kW} / \mathrm{m} 2]$ and $A_{p v}$ is area of the $\mathrm{PV}\left[\mathrm{m}^{2}\right]$. Global radiation data in Egypt was used as the input of the PV. Optimum area of the PV was determined according to the power the load. In this paper the used area of PV system is $1000 \mathrm{~m}^{2}$. Demand electrical loads for a stand-alone microgrid in Sharm El Sheikh City, Egypt as shown in Fig.4 (a) in a representative day each month. In this figure, peak values of demand are occurred in July and August while minimum values in March and November. Additionally, outside temperature and solar radiation in representative day each month are shown in Fig.4 (b), (c). In the present work, the hybrid system of PV, DEGs, and SOFCs is used to apply the requirements of the load with using of a genetic algorithm of parameters of individuals number is 2500 , generation number is 1000 , sampling time is 1 Hour, crossing probability with $95 \%$, mutation probability of $1 \%$ and selection $5 \%$ replacement of all individuals.

\section{ANALYSIS PROCEDURE}

The development of hybrid storage energy system with PV energy with large scale is proposed in this work for a remote community in a city, Egypt. The analysis of the characteristics of supplying energy to the demand side, as well as the technoeconomic potentialities of a hybrid system of PV, DEGs, and SOFCs with ammonia $\left(\mathrm{NH}_{3}\right)$ as a hydrogen supply for SOFCs is proposed. In this study, no batteries are used and the backup will be from DEGs or SOFCs. Two operating methods are suggested, the operation of DEGs or SOFCs with maximum rating in method 1 and remain of demand from the PV system (base load operation). The other is to apply the demand by using all out from PV system then the fluctuating operation of DEGs or SOFCs to supply remain of demand (power match operation). Battery is not introduced in this scheme. The two methods have been modeled; simulated and evaluated using the genetic algorithm and their performances are compared. 
The surplus PV power is supplied to the electric heat storage and the water electrizer. The amount of surplus PV power which is supplied to the water electrizer affected on the amount of stored hydrogen energy carrier and fuel consumption. Thus, the power used for hydrogen storage is optimized with the amount of DEGs deployed on an hourly basis.

The following analysis procedures are done:

1) The Genetic algorithm chromosome model for optimizing a stand-alone micro-grid as in figure 5. The chromosome model group in the objective functions to be minimal is the best. In addition, the genetic algorithm is used because only optimal solution that a designer does not consider might be obtained. Furthermore, the operation methods shown in this research is based on sufficient number of trial, and computer applies the optimal solution objectively.

2) The objective function of this work is minimizing the fuel consumption in the micro-grid. The micro-grid fuel consumption is extracted from the DEGs fuel consumption $F_{e g}$ from the following equation:

$$
\begin{aligned}
& F_{e g} \\
& ={ }^{e g} / \eta_{e g} * \eta_{g t}
\end{aligned}
$$

Where; $e_{e g}$ is the electrical power of the engine and $\eta_{e g}$, $\eta_{g t}$ are the efficiencies of the diesel and electricity generators respectively.

3) The efficiency of power generation and load factor for DEGs are calculated by Eqs. (11), (12). The DEG fuel consumption and heat exhaust from it is determined. Furthermore, heat required to supply water electrizer is showed. An electric storage heater and a hydrogen-carrier storage system are used to store energy are identified in this paper. Energy production is suggested in our proposal system by adding supply control with three sets of DEGs, SOFCs and large scale of PV output.

4) Three SOFCs are controlled to supply energy to the standalone micro- grid proposed in this work. The load factor and power generation efficiency of SOFC are calculated. In this study SOFC has the specifications of power generation efficiency is $50 \%$, efficiency of heat output is $40 \%$, Air fuel ratio is 3.0 , reaction temperature is $850{ }^{\circ} \mathrm{C}$, reaction pressure (gage) is $0.15 \mathrm{MPa}$, SOFC inverter is $95 \%$, utilization factor of hydrogen is $90 \%$, efficiency of air compressor is $55 \%$ and power conditioner is 90 .

5) The meteorological data in figure 4 referred to the output power of PV system. The random process is the property of the chromosome model. Based on the proposed algorithm the rate of DEGs and its fuel consumption and feeding the water electrizer with electricity are calculated. The balance of electricity is calculated from Eq. (1) to obtain the surplus PV power. After that, the amount of electric energy and thermal storage in the storage tank is shown. Step 3 is repeated for each DEGs and SOFCs.

6) The chromosome model extracts the SOFC exhaust heat and electricity output. The optimal variable that achieves the most economics objective function of less fuel consumption is obtained from the chromosome last generations.

\section{RESULTS AND DiscuSSION}

The output power from PV system in a representative day each month is shown in Fig.6. The total area of PV system is $1000 \mathrm{~m}^{2}$ with absorption rate of $70 \%$, heat transfer rate $10 \%$, and temperature coefficient of $0.4 \% / \mathrm{K}$, large solar PV generation capacity of $1.118 \mathrm{MW}$. In this figure, maximum out from PV system in June while minimum value in December. Results of operation with base load operation in method 1 are shown in Fig.7. In this is figure, operation of the proposal system with two cases, case one at which the three DEGs or SOFCs with its maximum output power of $3 \mathrm{MW}$ are supplied the demand side and PV power are used after that to supply the reset of demand as shown in fig7 (a). In this is case the operation of DEGs or SOFCs with its maximum efficiencies. On the other hand, in the second case, only two of DEGS or SOFCs are operated with its maximum setting and the third DEG or SOFC is fluctuated operation after used PV power as shown in fig7 (b). In method 1, there are a surplus power from PV system because we do not use all the output from PV as shown in Fig.7(c). The surplus power has its maximum value in May and September and its minimum values in July and August. This surplus power is used to supply the electric heat storage and water electrolyzed.

The PV systems monthly contribute mean power to the hybrid proposal micro- grid power system in case of method 2, with maximum and minimum of $1.1 \mathrm{MW}$ and $0.6 \mathrm{MW}$ in June and December, respectively, as shown in Fig. 8. The total power generated by all the generators (DEGs) was identify to be maximum in August and minimum in March. The annual diesel and fuel cell efficiencies variation with solar energy fraction is shown in Fig.8 (b) and (c). It is evident from these figures that PV power penetration has direct impact on them.

The exhaust heat from DEGs or SOFCs are supplied to heat storage tank to use it for ammonia synthesis operation as shown in Fig.9. In this figure, the performance of DEG operation in method 2 is shown. The load factor of DEG is illustrated in Fig9 (a) with high values in months May, June and July and less values in February and October. In additionally, the fuel consumption of the operating DEG in this method is shown in Fig9 (b).

Figure 10 shows the effect of PV power contribution on the performance of the system. In this figure, there is a comparison between the two methods and without using of PV system. The benefits of PV system are reducing $200 \mathrm{~m} 3$ of fuel consumption, that cause reduces annual consumption by $10 \%$. The proposed system with ammonia synthesis reduces monthly fuel consumption by an average of $25 \%$ compared with the same hybrid system without using NH3 as shown in Fig10(b). Due to dependence on increasing capacity of generation power from PV and improvement the efficiency of engine generator, the fuel consumption is decreased.

Figure 11 shows the energy analysis results for water electrolysis system, hydrogenation and dehydrogenation process. In this figure, $10 \%$ is the loss from AC-DC and DCDC conversion, $9 \%$ is loss from power controller and $16 \%$ is the loss from the water electrizer in the first stage of water electrolysis system. Then, in the second step in the hydrogen process, $19 \%$ is the electricity consumption, $9.5 \%$ is the loss of hydrogen process and $2 \%$ is the loss of ammonia synthesis 
unit. In the third step, $4.2 \%$ is the loss in the dehydrogenation process, and $7.5 \%$ is the heat supply to dehydrogenation process. The final step is the energy supply system. In this step, $3 \%$ are losses from gas off boiler, heat storage and back- up boiler. Also, 3\% is loss of SOFC. Thus, the largest losses come from water electrolysis process and hydrogenation process.
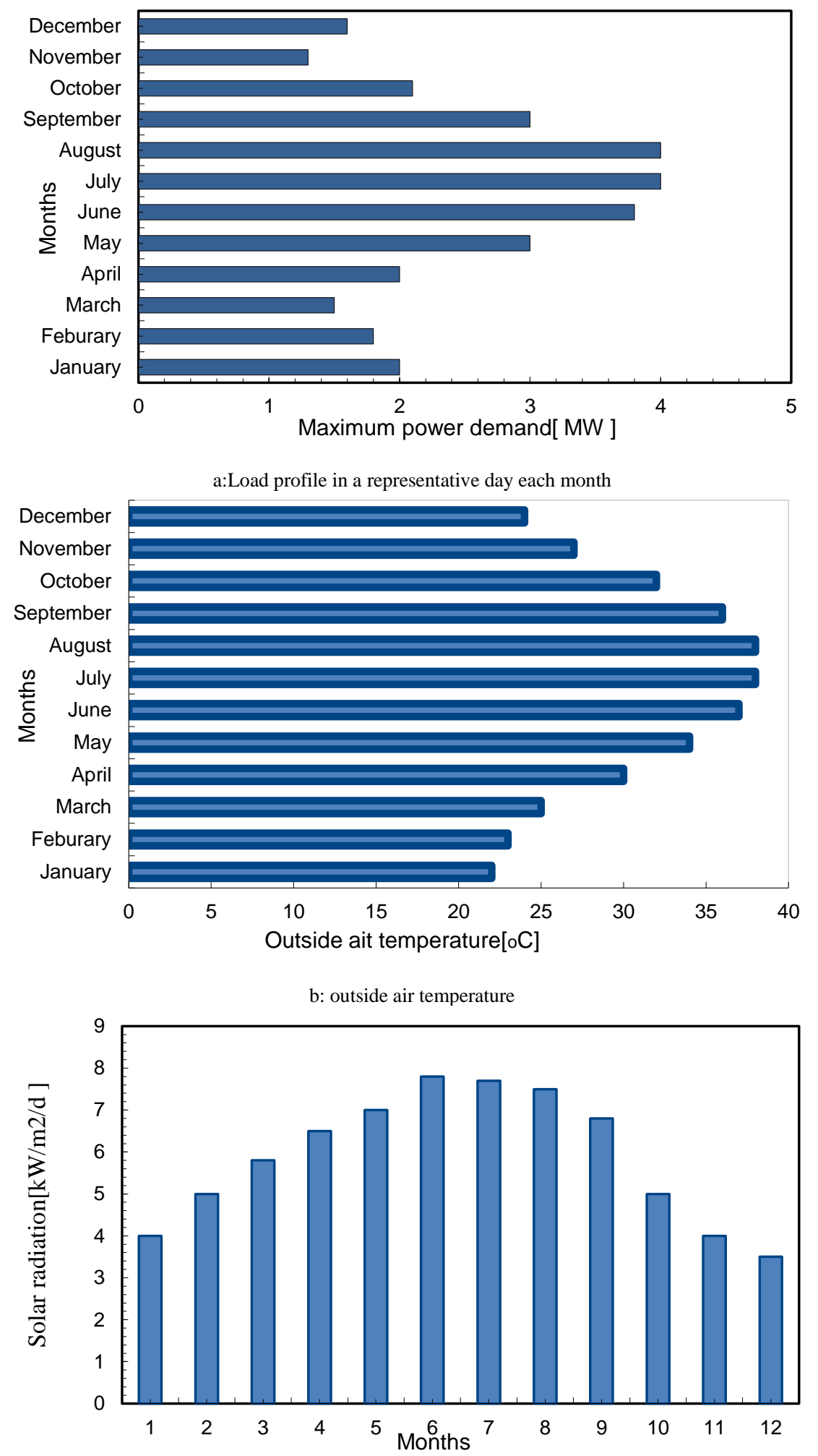

(C) Solar radiation

Fig.4 In a representative day each month (a) Electric power demand, (b) Outside air temperature, (c) Solar radiation 


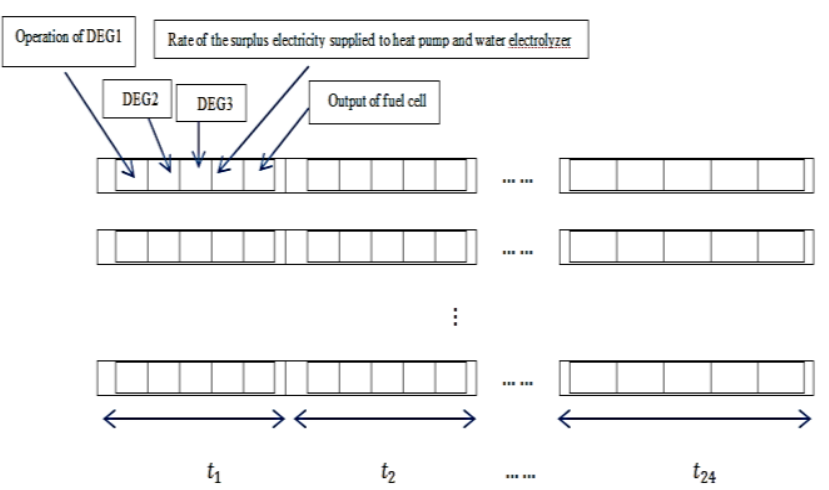

Fig.5 Genetic algorithm chromosome model for optimizing a stand-alone micro-grid.

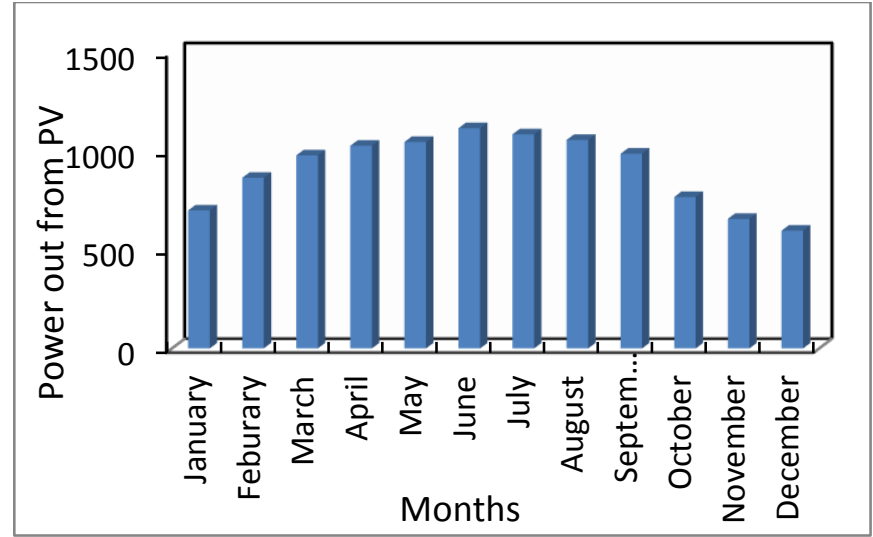

Fig.6 Output power from PV system in a representative day each month

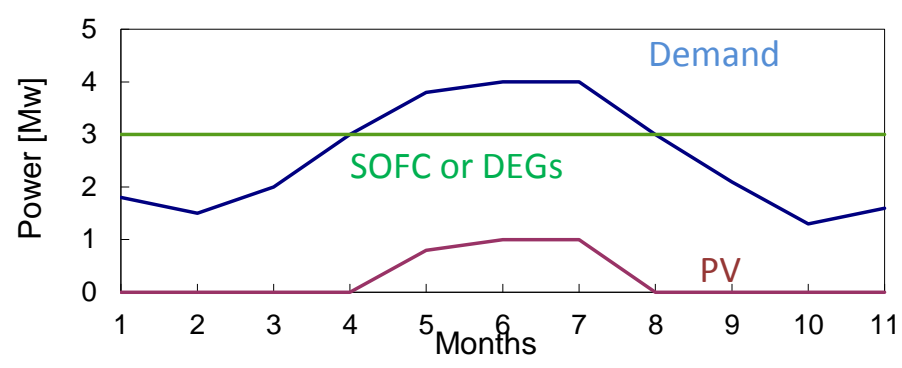

(a)

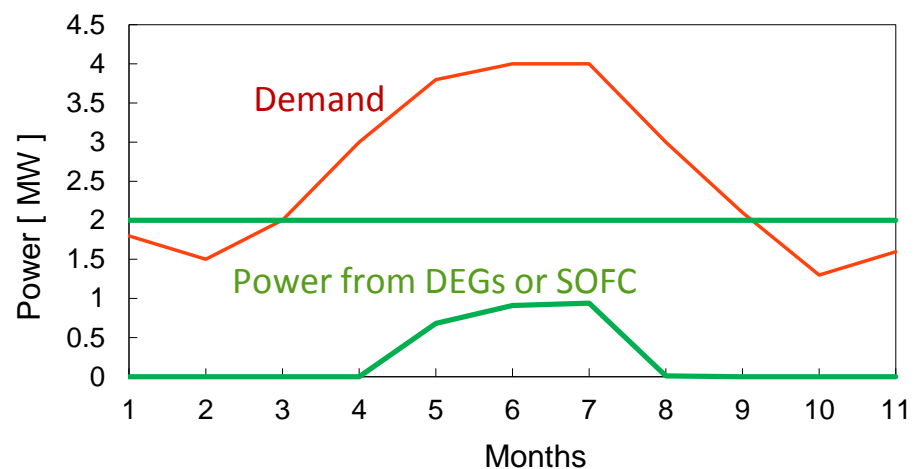

(b)

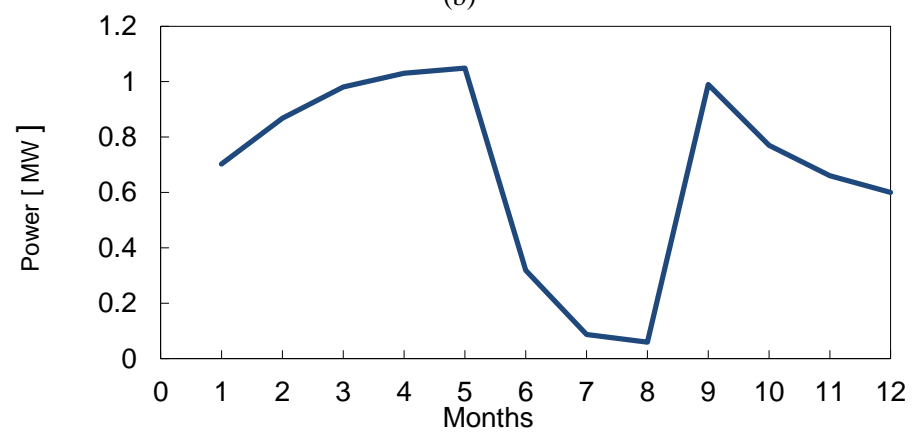

(c)

Fig.7 Method 1 at base load operation every month (a) maximum out from DEGs or SOFCs, (b)maximum out from only 2 sets of DEGs or SOFCs (c) surplus power from PV 


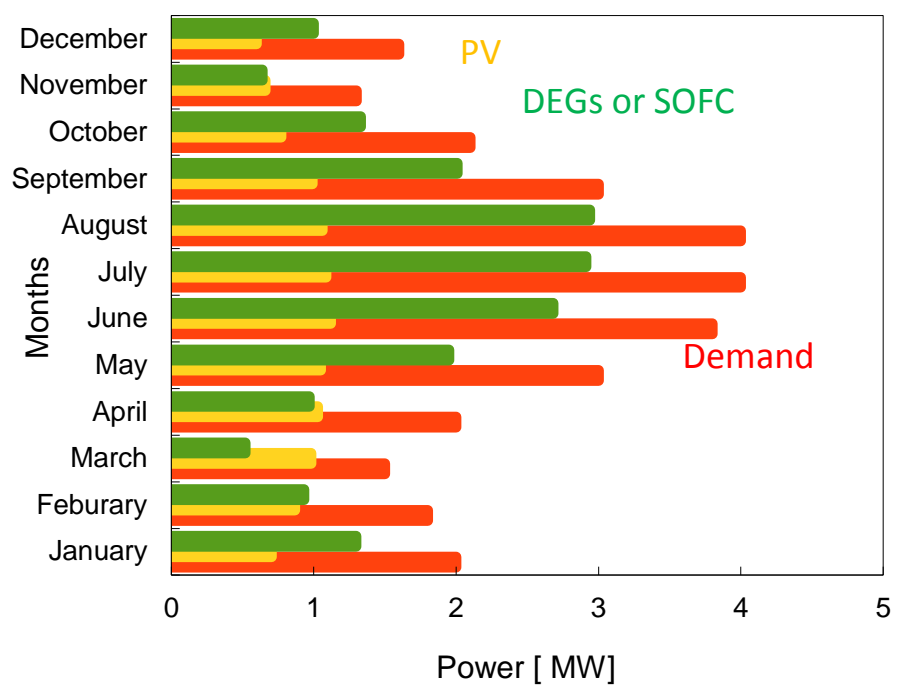

(a)

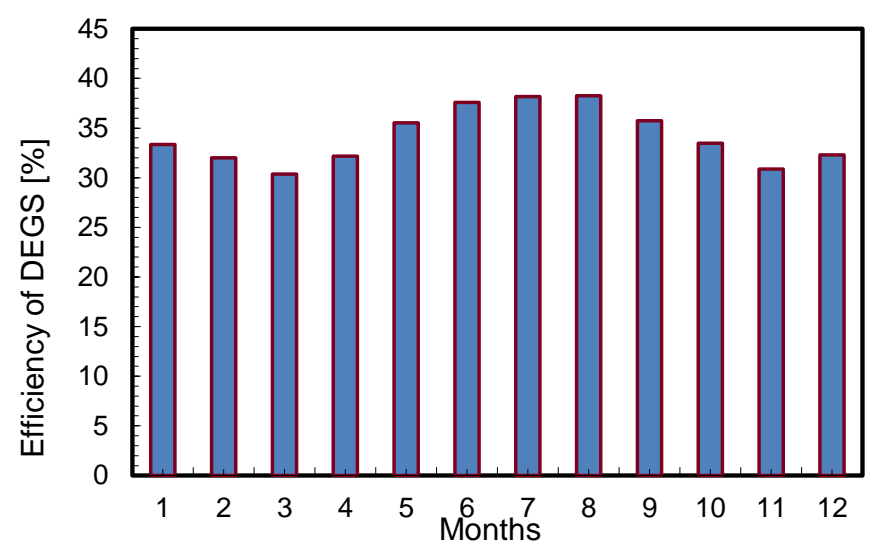

(b)

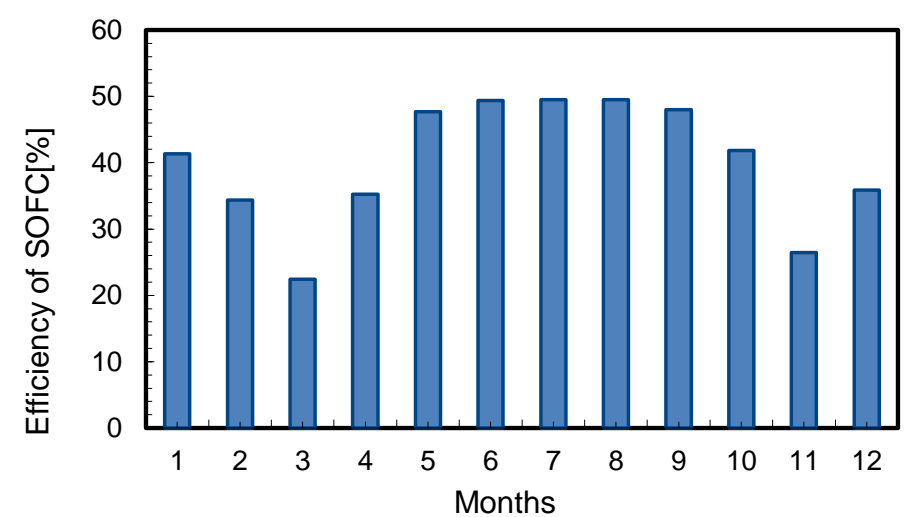

(c)

Fig 8 Method 2 at power-match operation every month (a) Output power from each supply, (b) Efficiency of DEG, (c ) efficiency of SOFC 

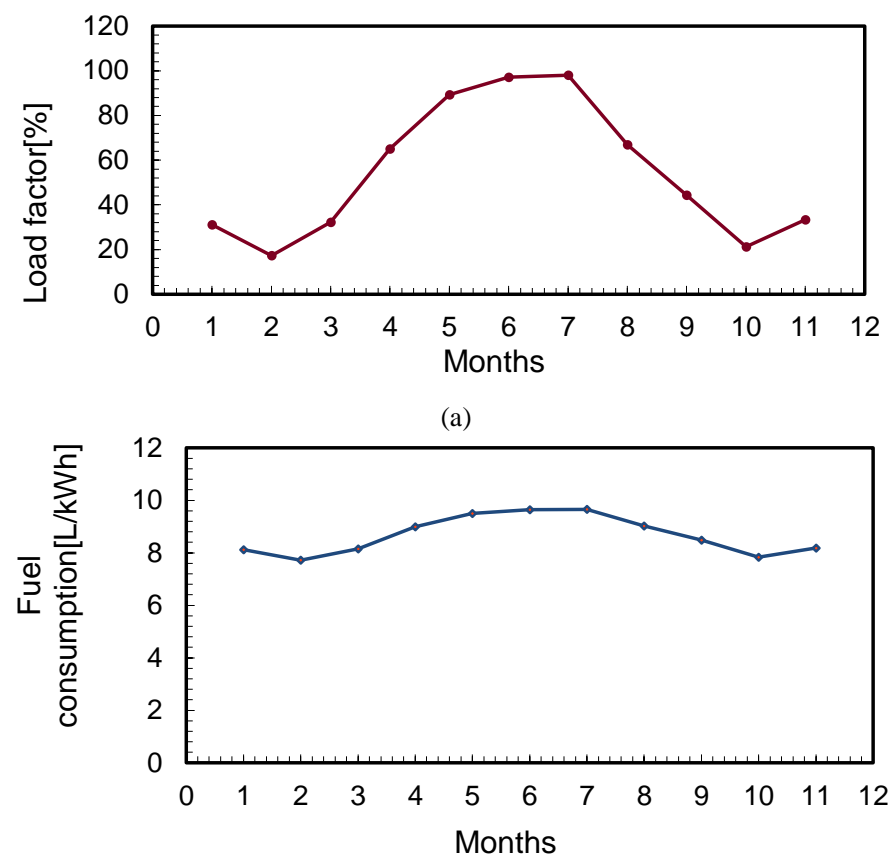

(b)

Fig.9 Performance of DEGs operation in method 2 (a) Load factor of DEG (b) Fuel consumption of DEGs

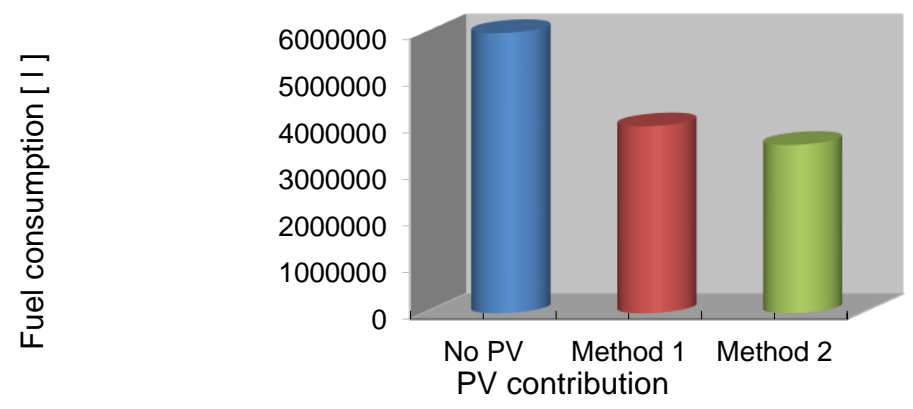

(a)

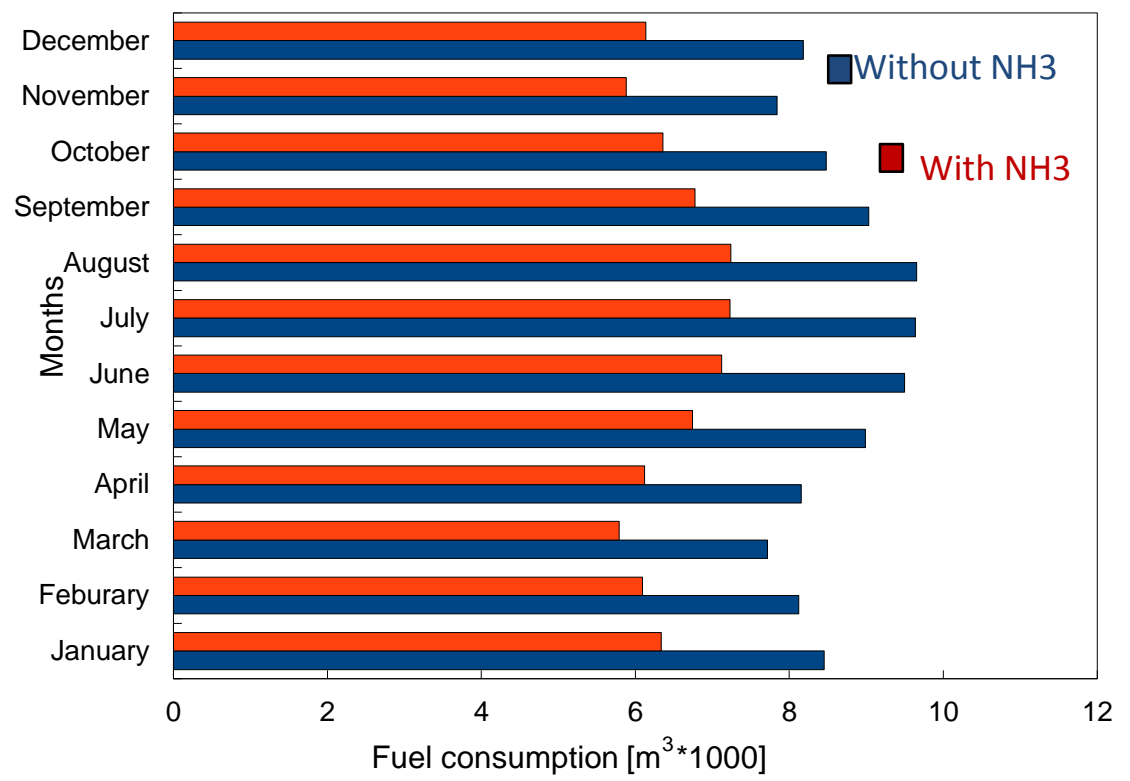

(b)

Fig.10 Parameters effect on fuel consumption of the system on a representative day of each month. (a) Effect of PV penetration on consumption, (b) Effect of using ammonia synthesis. 


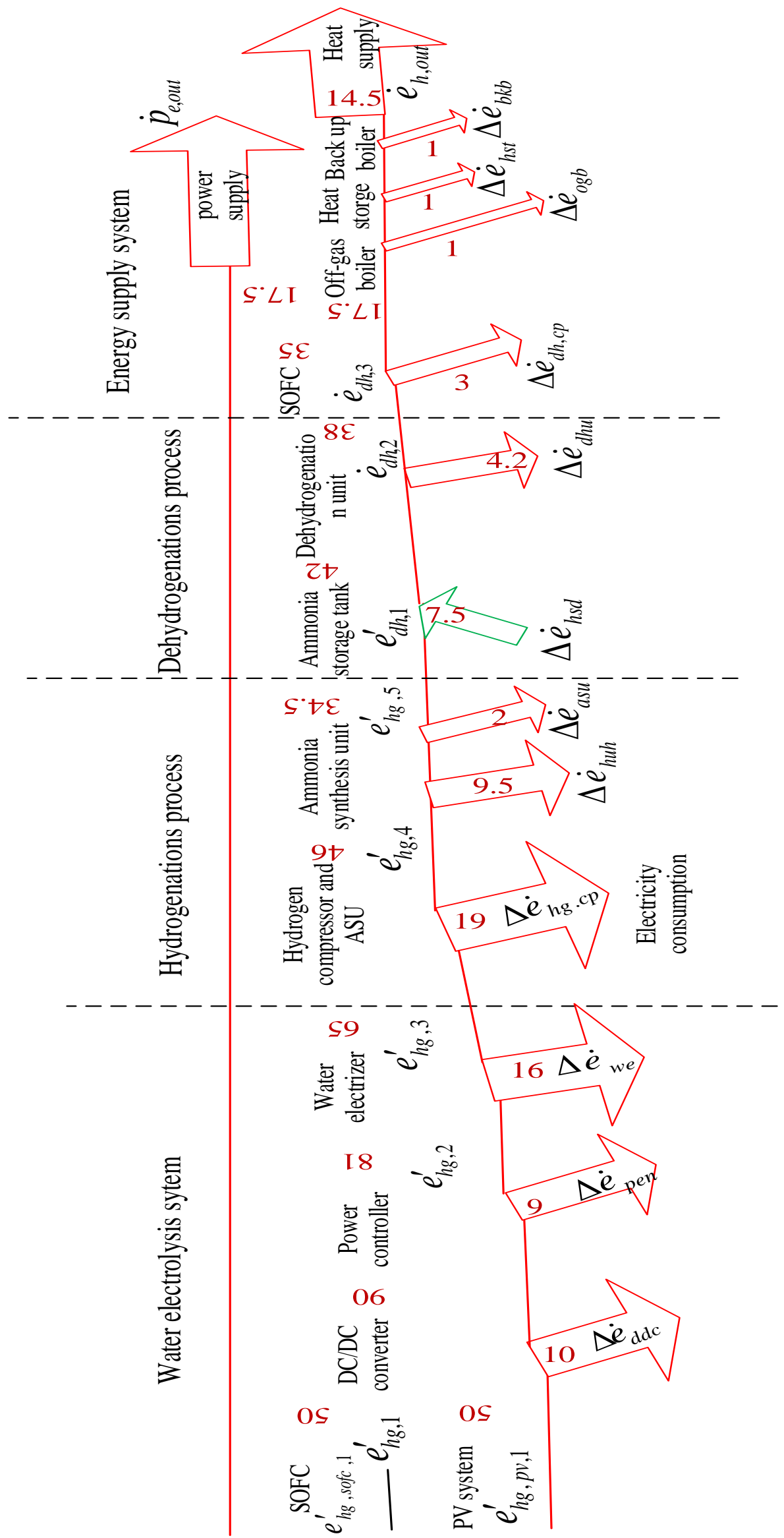

Fig.11 Results of energy flow for Ammonia process 


\section{Conclusion}

The techno-economic feasibility of a stand-alone microgrid with renewable PV energy and SOFC hybrid systems is evaluated in this paper. It is indicated the construction of a micro-grid of green energy utilization accompanied by power storage by ammonia. Moreover, it proposes method for optimizing an independent micro-grid that uses hydrogen carrier. It is investigated by a proposal system consists of engine generators (DEGs), PV system and fuel cells (SOFCs) to supply energy to a demand side in a city, Egypt. Two methods were analyzed in the proposal system. Once is the operation of DEGs or SOFCs with maximum rating and remain of demand from the PV system in method 1(base load operation). The other is to apply the demand by using all out from PV system then the fluctuating operation of DEGs or SOFCs to supply remain of demand (power match operation). Battery is not introduced in this paper so the surplus power from PV system in method 1 is used to supply the electrical heater and to the water electrizer. The two methods can apply the demand with highest profile compared to others hybrid system because we do not use high price of battery and using ammonia synthesis technology. In addition, the area of PV is large and many DEGs are introduced in this paper, the fuel consumption of the energy system of the proposal power supply system will decrease. A hydrogen supply using Ammonia $\left(\mathrm{NH}_{3}\right)$ is clarified. Furthermore, the loss of energy with percentage $45 \%$ comes from water electrizer, hydrogen compressor, hydrogeneration and dehydrogeneration. The electrolysis loss $16 \%$ of these energy losses, $15 \%$ of these is losses in hydrogenation and dehydrogenation losses are $12 \%$. In addition, the losses of electric energy conversion are $10 \%$ and $19 \%$ of the system energy is consumed compression of hydrogen.

This paper states that the reduction of fossil fuel can be obtained by using hydrogen energy supplly by $25 \%$. In addition, the analysis quantifies the improvements that can be gained with using fuel cell. Using a fuel cell (SOFC) tends to reduce the number of DEGs and this is process leading to reduce the fuel consumption of DEGs and improving the efficiency of the whole proposal system. Finally, these results showed that the modeling and optimization in this study for hydrogen carrier energy storage is effective for large scale of PV, DEGs, and SOFCs hybrid system. Therefore, when the green energy levels are increased in this research, the proposed power supply system will likely reduce the fuel consumption. Furthermore, this proposed hybrid system and the evaluated model can be replicated within a similar load with small scale of each component according to the demand side.

\section{DATA AVAILABILITY}

The data that support the findings of this study are available from the corresponding author upon reasonable request.

\section{AUTHORS CONTRIBUTION}

Abeer Galal: Software, Formal analysis, writing - original draft, Supervision. Mokhtar Said: Conceptualization, Resources, Writing - review $\backslash \&$ editing and final approval of the version to be published. All authors read and approved the final paper.

All authors are responsible for ensuring that the descriptions are accurate and agreed by all authors.

\section{Title in Arabic:}

تحليل شبكة صغيرة قائمة بذاتها من الخلايا الكهروضوئية , مولدات الديزل

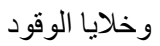

Abstract in Arabic:

هذه الاطروحة تقوم بتحليل نظام هجين مكون من الخلايا الكهروضوئية , مولدات

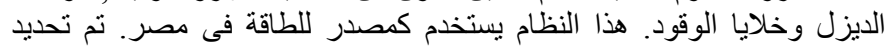

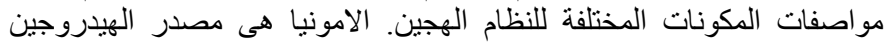

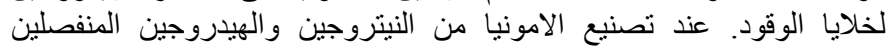

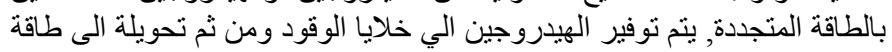

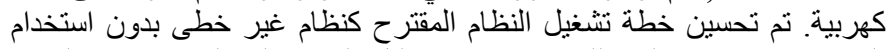

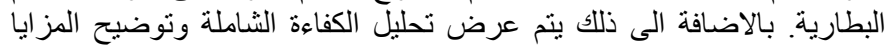

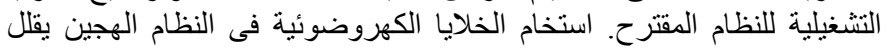

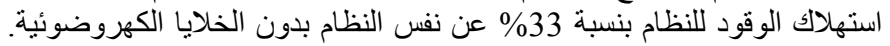

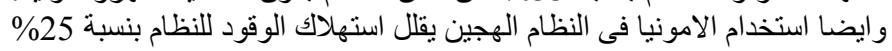

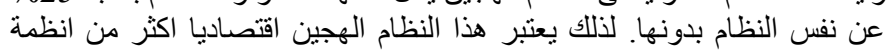

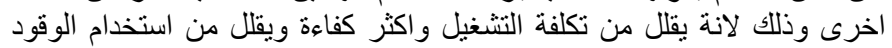

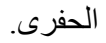

\section{REFERENCE}

[1] Jurasz, J., Canales, F.A., Kies, A., Guezgouz, M., Beluco, A., 2020. A review on the complementarity of renewable energy sources: Concept, metrics, application and future research directions. Sol. Energy 195(2020), 703-724.

[2] MS El-Negamy, MB Eteiba, GM El-Bayoumi,' Modeling and simulation of Egyptsat-1 satellite system powered by photovoltaic module', journal of American science 2013; 9(1):110-116.

[3] M Ei-Negamy, A Galal, GM Ei-Bayoumin, " Extraction of The unknown Parameters of a Photovoltaic Module From Manufacture Data Sheet", International Journal of Innovative Science and Modern Engineering (IJISME) 10 (2015), 6-13.

[4] Yinglong Bai, Runnan Yu, Yiming Bai, Erjun Zhou, Tasawar Hayat, Ahmed Alsaedi, Zhan'ao Tan, Ternary blend strategy in benzotriazolebased organic photovoltaics for indoor application, Green Energy and Environment, 2020.

[5] Hienuki S. Environmental and socio-economic analysis of naphtha reforming hydrogen energy using input-output tables: A case study from Japan. Sustainability 2017; 9:1376-1382

[6] Aki Hirohisa, Yamamoto Shigeo, Kondoh Junji, Maeda Tetsuhiko, Yamaguchi Hiroshi, Murata Akinobu, et al.: 'Fuel cells and energy networks of electricity, heat, and hydrogen in residential areas', International Journal of Hydrogen Energy 2006; 31, (8), pp.967-80

[7] Barelli L, Bidini G, Ottaviano A. Part: 'load operation of SOFC/ GT hybrid systems: stationary analysis', International Journal of Hydrogen Energy 2012; 37, pp. 16140-50.

[8] Shin'ya Obara, Abeer Galal El-Sayed.: 'Compound microgrid installation operation planning of a PEFC and photovoltaics with prediction of electricity production using GA and numerical weather information', International Journal of Hydrogen Energy, 2009; 34, (19), pp.8213-8222

[9] Barelli L, Bidini G, Gallorini F, Ottaviano A.:'An energetic-exegetic comparison between PEMFC and SOFC based micro-CHP systems', International Journal of Hydrogen Energy 2011, 36, pp.3206-14.

[10] Yan Z, Zhao P,Wang J, Dai Y. :'Thermodynamic analysis of an SOFCGT-ORC integrated power system with liquefied natural gas as heat sink', International Journal of Hydrogen Energy 2013, 38, pp.3352-63. 
[11] Shin'ya Obara.: 'Analysis of a fuel cell micro-grid with a small-scale wind turbine generator', International Journal of Hydrogen Energy, 2007; 32, pp. 323-336.

[12] Mikkola, M.: 'Experimental Studies on Polymer Electrolyte Membrane Fuel Cell Stacks ', Master's thesis submitted in partial fulfilment of the requirements for the degree of Master of Science in Technology, Helsinki University of Technology, 2001, pp.58-79.

[13] Abeer Galal El-Sayed and Shin'ya Obara.: 'Energy supply characteristic of the solar cell and diesel engine combined system with a prediction algorithm of solar power generation', Journal of Power and Energy Systems, JSME, 2010; 4, (1), pp.27-38.

[14] Shin'ya Obara: 'Power Generation Efficiency of an SOFC-PEFC combined System with time shift Utilization of SOFC exhaust heat', International Journal of Hydrogen Energy, 2010, 32, (2), pp.757-767.
[15] Ye L, Nayak-Luke R, Bañares-Alcántara R, Tsang E. Reaction: "Green" ammonia production. Chem 2017; 3:712-714.

[16] Meng L, Tsuru T. Hydrogen production from energy carriers by silicabased catalytic membrane reactors. Catalysis Today 2016; 268:3-11.

[17] Itoh N, Oshima A, Suga E, Sato T. Kinetic enhancement of ammonia decomposition as a chemical hydrogen carrier in palladium membrane reactor.Catalysis Today 2014;236-A:70-76.

[18] Trop P, Goricanec D. Comparisons between energy carriers' productions for exploiting renewable energy sources. Energy 2016; 108:155.

[19] Shin'ya ObaraRyo Hamanaka, Abeer Galal El-Sayed:' Design methods for microgrids to address seasonal energy availability - A case study of proposed Showa Antarctic Station retrofits', applied Energy, 2019, 236, pp.711-727. 